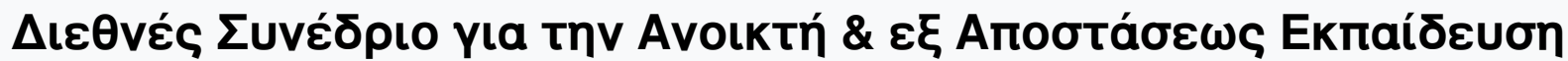

Tóp. 8, Ap. 2A (2015)

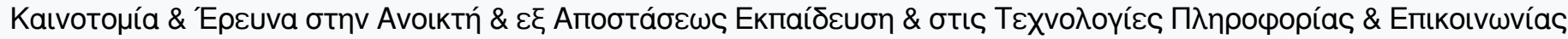

| Пракzіká

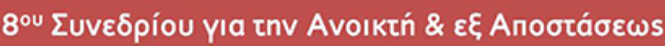

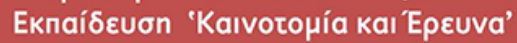

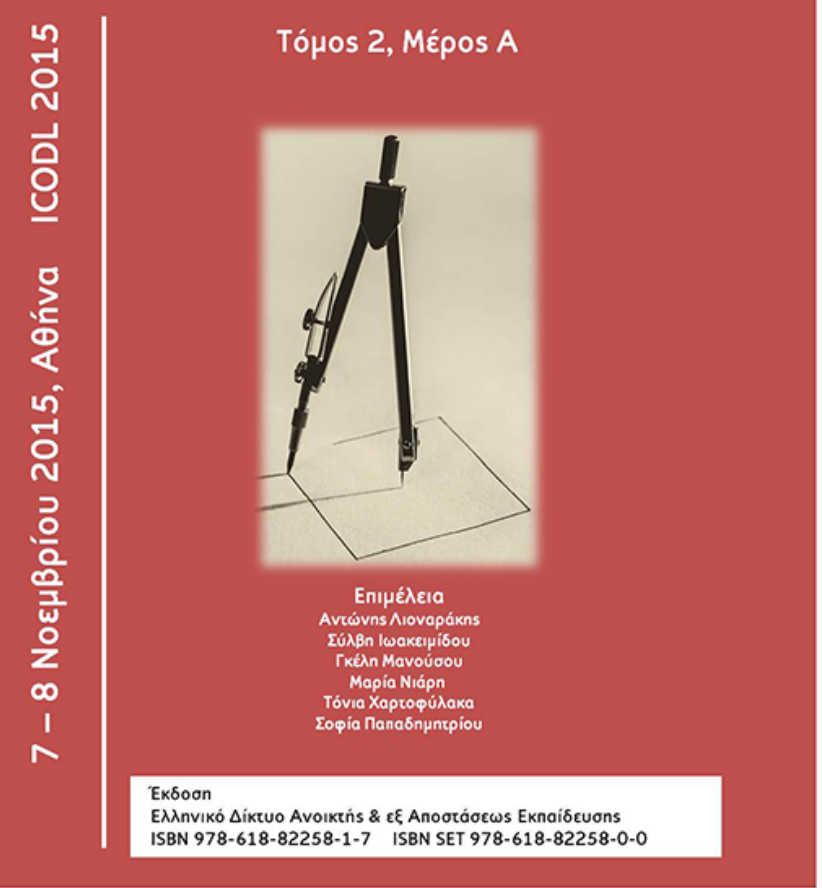

A reflection on why and how the use of advertisements can enable language learning in the (E)FL classroom

Maria Stamatelou

doi: $10.12681 /$ icodl.39 


\title{
A reflection on why and how the use of advertisements can enable language learning in the $(\mathrm{E}) \mathrm{FL}$ classroom
}

\author{
Maria Stamatelou \\ Freelance English, French and Spanish teacher translator, \\ interpreter and linguist analyst in Greece and the European Union \\ stam90@otenet.gr
}

\begin{abstract}
Advertising discourse is one of the society's 'most pervasive forms of discourse' (Delin, 2000: 123). Advertising discourse means a way of speaking about something, or an ideological standpoint from which a product, service or idea are launched.

This article is concerned with advertising discourse Critical Discourse Analysis (CDA) and how advertising discourse could be used in (E)FL coursebooks and classroom to contribute to language learning. Its central argument is that activities based on the discourse analysis of whole advertising texts provoke learners to '...pursue the social and cultural through attention to language' (Goddard, 2006: 1) contributing to their learning about language and their raising language awareness; indispensable steps before language learning takes place.
\end{abstract}

Key-words: Advertising discourse, language learning, language awareness, learning about language, teaching language at discourse level

\section{Introduction}

Evans and Green (2006: 222, cited in Johnstone, 2011: 188) state that words and grammatical structures are related within a frame which relates 'the elements and entities associated with a particular culturally embedded scene from human experience'. Also, Thornbury (2005: 6-7) argues that language is not realized as isolated sounds, or words or sentences but as whole text, spoken and written, and L2 language learners have to cope with texts because they live in a world of texts. On the other hand, Bax (2011: 9) shows the kind of knowledge people draw on when they comprehend language focusing on the diagrammatic form of Figure 1. All this means that grammar and words can only be interpreted in the context of the frame they evoke.

On the other hand, McCarthy and Carter (1994: vii-viii) argue that '...language teaching has to begin with texts and to recognize through them the forms of lexicogrammar... and how these wordings function in their particular patternings...' .

The overall aim of this article is to show why and how teaching language at discourse level using whole written advertisements contributes to L2 language learning focusing on commercial print advertising, for the practical reason that, as Picken (1994: 249) points out, it is more available than broadcast advertising. My preference for advertising texts emerges, firstly, from Delin's (2000: 123) argument that advertising language is one of society's most pervasive forms of discourse; secondly, from their frequency discussed in section 3; thirdly, from the results of a small scale mixed research study I carried out in five current EFL coursebooks of international type used 
in EFL classrooms (from intermediate to advanced level). The research data illustrated that the advertising texts are under-exploited qualitatively and quantitatively - Picken (1994: 2) had concluded the same twenty years earlier. Specifically, out of 64 units only 8 contained advertisement extracts not whole advertisement texts, while the function of their micro-level and macro-level discourse features were neither highlighted nor interrelated; Stamatelou, 2015 (2734).

My article is in the tradition of studies such as Hayland's (2007: 148-164) and Harman's (2013: 125-140) in which the authors show how genre pedagogies enable teachers to teach second language writing to support their learners to participate effectively in the world outside ESL classroom as well as how genre-based pedagogy in literature encourage language minority students to improve considerably in narrative and academic writing, respectively.

The rational of the structure of this article is as follows. Adopting Toolan ( 1988: 55) and Delin's (2000:127-8) argument that from the four advertisement components (namely, headline, body copy, signature, and slogan), the body copy does the main informative and persuasive work as well as Bhatia's (2004: 63) argument that advertisements exhibit some of the most innovative uses of lexico-grammatical forms, I focus on the body copy lexico-grammar of three print advertisements, located in 'The Economist' (2007) magazine (see table: 1), which promote different products/services (products hereafter). I, firstly, examine and discuss their body copy lexico-grammar the advertisers use to describe and evaluate their product, and to build the nature of 'The Economist target readers' - and by extent potential consumers (readers hereafter, while advertisers and readers: participants hereafter) -desired consuming identity in terms of the advertised product; section 2 .The aim of this process is the identification and reviewing of certain illustastrative macro-level and micro-level advertising discourse features that will enable me to support the contribution of teaching language at discourse level using whole advertising texts to language learning.

Then, I discuss why the study of commercial advertising texts is important for EFL learners in the western societies devoting attention to what learning about language and language awareness are; section 4 . In section 5, I discuss why the teachinglearning process of highlighting the macro-level and micro-level discourse features at discourse level using whole written advertisements enables learners to achieve native speaker proficiency in the target language focusing on language learning concerns and culturals concerns. In section 6 I discuss teaching implications focusing on form, function and sociocultural parameter.

down

Level Type of Knowledge

$\downarrow$

Macro-level aspects (higher order features).

$\downarrow$ WORLD

Shared world knowledge.

SOCIETY AND CULTURE Socio-cultural knowledge: social relations and roles

CONTEXT

TEXT AND GENRE
Pragmatic knowledge and various contextual information

Intertextual relations; Genres (including

function and structure of genres);

Discourse modes 
CONCEPTUAL Mental models; Schematic knowledge

STRUCTURES (schemas, frames and scripts)

Micro-level aspects (lower-order features)

$\begin{array}{ll}\text { COHESION } & \text { Cohesion and cohesive devises } \\ \text { SENTENCE } & \text { Syntax } \\ \text { WORD, CONCEPT } & \text { Lexis, Concepts } \\ \text { ELEMENT } & \text { Sounds / Letters or Script }\end{array}$

$\boldsymbol{U p} \uparrow$

Bottom-

Figure:1

Bax'(2011: 9) diagrammatic form

\section{The examined advertisement research rational}

This is a small scale CDA qualitative study following a 'convenience sampling' (Miles and Huberman, 1994, cited in Dörnyei, 2011: 129) combined with analytic generalization so as to have the potential to offer valid results as any other research. My method aspires not to be narrowly descriptive - say analysis of verbal as object which seeks merely to describe the features of the phenomena. Focusing on illustrative macro-level and micro-level discourse features, I attempt, through thick description and analysis of each advertisement body copy separately, to formulate how the micro-level of interaction (lexico-grammar) fits with the macro conditions and dimensions which govern those micro-levels.

\begin{tabular}{|l|l|}
\hline Source: The Economist: $28 / 2 / 2007$ & Page(s) \\
\hline Advertisement conventional Name for this paper demands & \\
\hline CHANEL & $24-25$ \\
\hline Emirates & 117 \\
\hline VTB & $122-123$ \\
\hline
\end{tabular}

Table: 1 Advertisement name and location.

Simultaneously, adapting Fairclough (2009:211), I consider that the advertisers of the selected print advertisements (advertisements hereafter), firstly, know that they have to construct and establish their product as 'different' in a market where the majority of the marketed products are rather similar. Secondly, they know that categories of potential consumers, even grouped and described as 'The Economist' readers, are often not specifiable in terms of independently existing types of social membership (ethnic group, gender, etc.).

I define commercial advertisements as the written texts with which advertisers (producers and/or copywriters) want to capture readers' attention aiming to get them to register their communication either for purposes of immediate action or to make them more favorably disposed to the advertised product, service or idea. Goddard (2006: 9) sums this up saying '....copywriters have to find ways to shout at us from the page'.

\subsection{Findings and discussion}

In this section, firstly, I present briefly the advertisement headlines, because they act as a springboard to attract readers' attention, and read on the body copy. Then, I describe and discuss each body copy lexico-grammar separately. 


\subsection{Headlines}

The examined advertisement headlines are eye catching and intriguing, and may interact with their images. For example, 'One continent.' (image: 2) connoting land (almost) surrounded by sea, interacts with the connotation of its image seascape in a punning way. Concerning 'CHANEL' (image: 1), the image itself acts as a headline because the vigorous young man who is enjoying sailing is wearing a sport CHANEL watch (CHANEL wearer hereafter). Thus, readers are "CHANEL trapped" perhaps thinking that a CHANEL watch is being advertised. All headlines vaguely create a reality for the advertisements and establish criteria by referring to readers' needs; e.g. 'One continent' and 'CHANEL' exist; 'a group of banks' disruption took place and 'a Bank Group' emerged (image:3). Indeed, they vaguely a) assert verifiable facts about the world and the product; b) describe feelings, actions and a state of affairs. Actually, they somehow promise to tell why: 'One continent'; 'a Bank Group'; the 'CHANEL' watch wearers are real. Through this practice, readers are made to ask common- in every day discussion- question types, for example, 'Which Continent?'; 'Which Bank group?'; 'How could I be like him?', respectively. Thus, they become hooked wanting to read on the body copy to have the mystery solved while start being implicated in a 'conversation' with the advertiser.

\subsection{CHANEL Body copy}

'CHANEL' body copy (image: 1) consists of four words (CHANEL; ALLURE; HOMME; SPORT) printed in the form of a list on the bottle which contains the product, arouse various connotations. Specifically, 'CHANEL' the corporation trade name, in the bolt bolting, acts as 'tickler' (Cook, 2006:106)title facilitating the advertiser to start describing the perfume in terms of its effects and the person who may use it, while portraying the CHANEL wearer who is incarnating readers' man archetype. Perfume descriptions reflect the participants' individual knowledge as well as to what extent this knowledge can become shared between them. The advertiser uses them as indices to construct a 'friendly' tête-à-tête between participants, based primarily on 'ellipsis' (there is no room for misunderstanding) in order to establish readers' needs and corporation credentials. An illustrative example is as follows: (A: Advertiser; R: Reader),

-R. How could I be like him?

-A. That's why there is CHANEL. [The reverse "WH-cleft" presupposes that there is 'CHANEL' and the reader knows 'CHANEL'].

-R: Why CHANEL?

-A: To ALLURE; To be HOMME; To be a SPORT.

'ALLURE' -the product trade name - implies 'to attract' and 'entice' by pleasing and seductive qualities. It also suggests enticement into danger e.g. the implication of a siren's attraction is always conveyed. 'ALLURE' (either as verb or noun) evokes positive association and evaluation for the product, since it stresses the overcoming of resistance or indifference by using winning methods, such as the enhancement of the reader's charms through the use of 'ALLURE' perfume. The recognized French word 'HOMME' emphasizes the cradle of exceptional perfumes and, following Petit Robert (2007: 1243), the for eternity male psychology. Also 'Be a 'SPORT', connoting a complete release from work and seriousness, as well as indulgence in that which cheers and entertains, reflects the CHANEL wearer who is enjoying an exciting activity straightly related to wealth as well as physical and mental skills. Thus, the potential 'ALLURE' user can usually react well and cheerfully, therefore, he would be a fun to be with. 


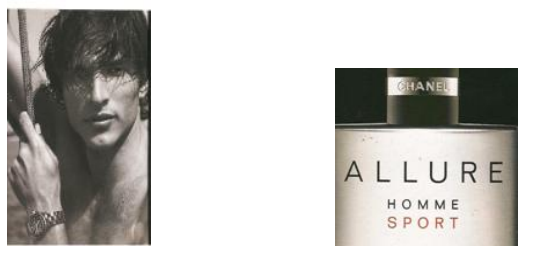

Image: 1

\subsection{Emirates Body copy}

The three sentence 'Emirates' body copy (image: 2) consists of thirty eight words. The first sentence 'The world's continents were once all joined together as one', acting as mimicked face to face interaction a) presents the advertiser as having guessed the readers' question: 'which continent?', and starts solving the mystery for them; b) further asserts shared knowledge facts about the world between the participants; c) makes the proposition for the reader uncontroversial and unarguable, because of the definite article 'The'. Indeed, even, if the reader answered: "no, there weren't" the proposition remains true - the world has had continents. Also, 'Once' meaning 'in the past, but no longer'- implies the evolution of the planet earth, namely, "The world's continents are no longer all joined together as one." This evolution facilitates the advertiser to establish vague readers' need(s) implying that many continents impede readers' effortless transportation. This idea is emphasized by 'join' which evokes positive association and evaluation for the product, since it emphasizes equality between continents. Indeed, 'join' is used when one enters into the company of others as equal; e.g. join a society; church, etc. Thus, readers are made to 'need' the world's continents being joined together (again) and borders be flexible. Now, the advertiser through the phrase 'And ... they shouldn't be again' gives a 'common sense solution' to the readers' need without mentioning the 'joining' service. Thus, $\mathrm{s}$ /he allows readers to accept the 'joined again' practice and solution as a sensible one, because of referring to emphasized asserted facts. Indeed, firstly, 'again', acting as conventional implicature, emphasizes the asserted fact 'The world's continents were once all joined together as one'. Secondly, the discourse marker 'And', being at the beginning of the sentence, practice borrowed from spoken language, has a double function. Firstly, 'And' is positioned as theme, thus, the elliptic activity: "joined' again' is in a focal accentuated position. Secondly, 'And', signaling coherent links between two parts of a topic, gives the illusion that the advertiser negotiates his/her way through talk checking whether s/he shares a common view of the topic and the nature of the unfolding discourse with the reader. Thus, the impression of logical argumentation is highlighted.

Now, the reverse wh-cleft: "Which is why Emirates now serves more than 80 destinations across the world...' conveys the presupposition that 'we have created Emirates service for some reason'; specifically, 'we 'now' air-join 'more than 80 destinations'. On the other hand, 'Over...', implying that there are at least 100 nations, establishes a further side need related to readers'( as international travelers) effortless transportation. Explicitly, readers appear to need crew who apart from speaking English (international language), they speak readers' native language and share their national culture. Also, 'now', implying 'not before' with 'serves' (simple present implying that the act 'serves' is performed repeatedly as well as now) and '... more than...' (implying that until now Emirates have been serving at least 80 destinations), establishes corporation credentials reflecting Emirates' experience in air-linking the world and knowledge of their international clients' needs. Furthermore, the solution sounds as 'Emirates' promise to further increase the crew 
nations and destinations. This wh-cleft improves the neatness of fit between a common sense solution to the readers' need for some service and Emirates which are/offer this service. Indeed, wh-cleft acting as if a 'but how?' reader's question were answered by the invisible advertiser, further gives the feeling of some logical unfolding discussion between participants. This impression is heighten by the use of 'which', which, referring back to something that the reader either has asked or not, gives the impression that the reader is included in the 'conversation'.
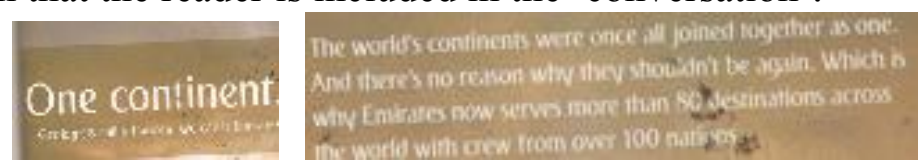

Image: 2

\subsection{VTB Body copy}

The twenty seven word VTB body copy (image: 3) consists of two parts. Firstly, 'VTB' (the corporation trade name), through which the advertiser shows the effect of the disruption (discussed in 2.2). Indeed, the headline + VTB act as a sequence of an Equilibrium $\rightarrow$ Disruption $\rightarrow$ Return to Equilibrium. The two equilibriums, being similar but not identical, make readers further hooked to read on the second part to know how and why the disruption happened. Secondly, the one sentence second partconsisting of a string of verbs, nouns, and two gradable adjectives- establishes credentials for the corporation and needs for the reader informing about the :

1. Corporation's motivation: 'Motivated by the fresh challenges'. 'The fresh challenges' is the accentuated agent of the pseudo-passive structure, while 'the' presupposes that even if readers contradicted 'the fresh challenges' they could not contradict that 'VTB' is motivated by some 'challenges'. Also, 'fresh' acting as conventional implicature, implies so 'new challenges' that they have not had time to show their newness, energy and virginal quality. Indeed, 'fresh'- having a range of different positive connotations such as new; original; clean (pure)- collocates with water; memories, weather, colors, etc., and applies to some classes of edible or decorative things; appearance; feelings; experiences .

2. Corporation's firm but not fully mentioned decision: 'have set ourselves';

3. Procedure: The phrase 'we are consolidating, our experience, knowledge and strength' indicates that the advertiser has in mind not so much to emphasize the objective fact as the aspect of the fact. Indeed, the act of 'consolidating' is seen as uncompleted and perhaps never stopping as it presupposes that "we had experiences, etc....' and also implies that "we have and will have experiences, etc." Also, 'and' expresses a logical order and relationship between the noun phrases signaling explicitly that their order connotes an evolutionary dynamic sequence.

4. Decision's sequential achievement: 'to move forward, attain new heights and expand your horizons'. Here, the advertiser uses the imperatives to engage the reader into the construction of interpersonal information facilitating 'an intimate, interactive addressing of the reader... in a conscious way' (Toolan, 1988:54). Thus, readers are made to think about and remember the message. The three statements joined by 'and' contain action-related dynamic information and result as 'and' = 'and then'. Also, 'forward', 'new' and 'expand' have positive affective meaning and imply continuity. Specifically, 'forward' and 'new' imply and presuppose that 'motion' and 'heights' respectively are not something new for the corporation, -thus, further establishing credentials- while 'expand' presupposes that you (reader) have already horizons which you want to expand (need establishment). 
'And' in 3 and 4 above, following Yule (2005:46), acts as implicature and marks how each connotation leads to or back to another, and is exploited to give a sense of logical unfolding argument which is very useful in the "reason why" style argumentation of the advertisement, because a cogent case is made for the reader to show interest for the improving image of the corporation. Indeed, if the parts joined by 'and' were reversed, there would be a big change in meaning, especially in 4 . In 2; 3 and 4 above, through the interpersonal ['we; ourselves' ;our' ; 'your '] orientation, the 'we; ourselves' ;our' is presented as the provider, the one who can fulfill readers' individual need and the 'your' as the beneficiary. The party addressed 'your' is representing an individual specific reader who the advertiser seems to address directly as if they were present. Thus, the advertiser not only involves reader(s) in an apparently conversational, equal relationship way, but also puts them in position of a well identified need: 'expand your horizons'. Now, although the simulated address, through the conversational device 'Your', 'remedies impersonality' (Fairclough, 1989: 128), 'your horizons' are not specified. On the other hand, the advertiser appears to have created the Bank Group VTB because s/he had known readers' need. This need, being established after the establishment of the corporation credentials, appears to be long standing shared knowledge between the participants. The information, having no full stop, but commas, further emphasizes the impression that the speech is natural evoking a close peer-group relationship.

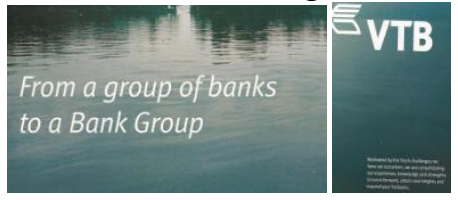

Image: 3

\subsection{Body copy conclusion}

The advertisers knowing that written advertisements are impersonal mass communication, and advertising relationship is inherently unequal because there is no real two -way conversation, they use body-copy lexico-grammar to establish 'interpersonal relationship, trust and goodwill' Myers(1994:112) between them and the readers so as to downplay power differences, and their selling activity. Indeed, the advertisers use dexterously lexico-grammar to build concepts readily available to readers who, in turn, identify themselves with the product, and even collaborate in "building" its image through accessing concepts that are native to them. Namely, readers are involved in the establishment of corporation credentials and readers' needs. Or, following Fairclough (1989, 197-208), advertising implements its functions (sell) using language to build images, consumers and relations.

\section{Teaching language using whole advertisement texts}

The study of commercial advertising texts is important for EFL learners in the western societies, among others, for the following reasons. Learners cannot walk down the street, shop, watch television, read a newspaper and so on without encountering commercial advertising texts written either in English or in their L1. In both cases, they usually advertise products or services found all over the world, such as journeys and cars, the majority of which attract learners. The frequency of advertising texts is supported by Thornbury and Cook. The former (Thornbury, 2005: 6) argues that on average people, in the western societies, are exposed to 'anything from 600 to 1600 ' advertising messages a day, while Cook (2001: 1) says that the prominence and quantity of advertisements would strike a stranger to our society, let us say a Martian, and s/he might reasonably pay more attention to them than to texts 
that people value more highly such as literature and law. Also, advertisement texts are creative due to their using- as it was shown in the indicative invastigated advertisements people's- commonly shared language resources in ways that affect them and mean something to them, thus, learners may enjoy advertisements and be motivated by them, while their analysis may stimulate their creativity.

Moreover, adopting and adapting McCarthy and Carter (1994:150), advertisements are a valuable source of habits, customs and social behavior the knowledge of which takes place through learning about language; namely, through discourse analysis, indisputably the route is bidirectional. On the other hand, the dynamic process of language learning emerges from language awareness, while language awareness emerges from learning about language. Therefore, the highlighting of the macro-level and micro-level discourse features of advertisement texts at discourse level contributes to develop learners' language awareness which leads to language learning. Also, through this kind of highlighting learning becomes a process of devolving selfawareness of the world outside the classroom. This might, also, contribute to language learning, because devolving self-awareness, namely reflecting their consumer attitudes, and meeting frequently the same or similar advertisements around them either in their L1 or L2, learners become motivated, because learning English stops being limited to the classroom but 'escorts' learners in their daily life (sub-sections 5.1 and 5.2).

Language awareness, learning about language and the contribution of teaching language at discourse level using whole commercial advertising texts to language learning will be discussed in the next sections to support certain teaching implications regarding indicative suggestions about how advertisement texts could be included in the design of EFL coursebooks and/or exploited in EFL classroom.

\section{Learning about language and language awareness}

Learning about language is, according to McCarthy and Carter (1994: 22, 89, 134), a process of analysis, explicit attention to language, conscious reflection on the forms and functions of the language and on the means by which meanings are made by language. Thornbury (2002: x) argues that learning about language enables learners to promote their language awareness, which is humans' sensitivity to and conscious awareness of the nature of language and its role in their lives. Thus, the focus of language awareness encompasses not only the linguistic domain, for example, the grammar of language, but also the cultural and sociolinguistic domain. For example, considering the sentences:

-'I suppose he's quite a nice little boy, isn't he? (Tentative, polite)

-Nice kid. (Informal, spoken)' (Hedge, 2008: 157).

$\mathrm{Tt}$ is clear that in English the available different grammatical structures for a particular purpose are not equivalent, since they belong to different styles. Style is a matter of lexis and grammar or, what Johnstone (2011:138) argues, the repeated sets of stancetaking moves associated with situations or social identities.

In second language education language awareness refers traditionally to linguistic knowledge only. McCarthy and Carter (1994: vii-viii) argue that one of the routes to achieve language awareness is through language analysis, that is, analysis carried out by learners in whole texts; '...language teaching has to begin with texts and to recognize through them the forms of lexico-grammar... and how these wordings function in their particular patternings...'.Thus, language analysis contributes to learners' linguistic and sociolinguistic competence (language knowledge of what language is correct in a given situation for a given purpose). To conclude, grammar 
choices are related to larger issues than that of the sentence and the lexicogrammatical system and the discourse patterns of a language are strongly interrelated, and all language should be thought of as discourse. In section 2 there are examples and discussion related to how advertising carries out its functions exploiting the kind of knowledge people draw on when they comprehend language.

\section{Why using advertisements to teach discourse}

In this section, adopting Goddard's (2006: 3) argument that advertisements leave messages behind them about the culture that produced them, I discuss how and why the teaching- learning process of highlighting the macro-level and micro-level discourse features at discourse level using whole written advertisements contributes to raising learners' language awareness, enabling them to achieve native speaker proficiency in the target language (language competence), as it may pay great dividends in terms of memory and understanding.

\subsection{Language learning concerns}

The contribution of written advertisements to language learning, after their being used to teach macro-level and micro-level discourse features at discourse level, seems to be significant, because, in an era of globalization and information technology revolution, advertising is an unavoidable fact in today's consumer society as it is omnipresent trying to sell the same or similar products. That means that learners may meet the same or similar advertisements to those they have analyzed at discourse level in their classroom in their native language (L1) and in L2/English (target language) all over the world through various channels such as print and audio as a large percentage of similar goods are sold universally and their advertisements are in learners L1 or/and in English (the commerce language universally). Also, learners may meet the same taught discourse features in various other genres with the same or different function. This last is due, as Goddard (2006: 51-2) points out, to the fact that because advertising needs to attract people's attention, and to be memorable, advertisers make connections between advertisements and other texts well known in their culture. One way of doing this is to play with the language code and to use poetic devices or linguistic features of everyday language, for example, the elliptical utterances of 'casual conversation' as discussed sections: 2, and supported by, for example, Cook (2009: 115), Picken (1999: 251-2), Goddard (2006: 51-9) and Delin (2000: 135). Cook $(2009: 33,39)$ calls this advertising 'behaviour' 'parasitic upon...other genres' elucidating that it is neither a negative quality, nor unique to advertising. For example, James Joyce's novel 'Ulysses' is 'an assembly of a range of styles -newspaper, romance, ...".

Therefore, learners who have already been taught discourse features at discourse level using whole written advertisements, may compare their L1 and L2; comparison of L1 and L2, leads to intake 'the processing of assimilating linguistic material' (e.g. Gass, 1997: 3-5). Also, meeting the same discourse features, in the same or other genre, learners may compare their function in these genres with reference to prior knowledge. Comparison to prior knowledge and frequency in input leads to 'apperceived input' (e.g. Block, 2003: 27) which is the first stage during which learners notice incoming data, relate them to past experience and then parse them into meaningful units for further analysis.

To conclude, considering the frequency of advertisements and their 'parasite' discourse, their exploitation to teach discourse in EFL classrooms may contribute to language learning. 


\subsection{Cultural concerns}

In sections 3 and 4, it is discussed that language awareness, which leads to language learning, encompasses the linguistic, cultural and sociolinguistic domain. In this subsection, I define culture and I briefly discuss how culture is related to the other two domains in advertising discourse. McCarthy and Carter (1994: 150,159) define culture as the set of prevalent values and beliefs within a given society or section of a society, arguing that adopting a cultural view of language means exploring the ways in which forms of language, from individual words to complete discourse structures, encode something of the beliefs and values held by the language users. Fairclough (1992: 6) backs this view saying that language use reflects culture and it is impossible to disassociate the two in any real sense, that is, the way a culture sees the world is reflected in its language and vice versa.

Concerning language teaching McCarthy and Carter (1994: 151) give culture three more specific definitions. Firstly, culture with a 'capital C' which includes the most prominent artistic achievements of a society such as art, music and literature. Secondly, culture with a 'small c' which includes advertisements, jokes etc. and refers to the vast area of a specific society's habits, customs, social behaviour and world assumptions. In the examined advertisements, for example, CHANEL is portraying how the CHANEL wearer is incarnating readers' man archetype.

The third definition is 'culture as social discourse' which concerns the simultaneous knowledge of the language system with the social knowledge and interactive skills. For example, knowing rules about the cohesive device of 'ellipsis' (see sections 2) has no value if learners do not know how to use 'ellipsis'. The former is 'conscious knowledge' which is not 'equivalent to language use' (ibid: 161).

\section{Teaching implications}

This section has illustrative implications regarding how coursebook designers and/or teachers could look at advertisement text and the kinds of activities it generates in (E)FL classroom to raise learners' language awareness and promote the dynamic process of language learning. A discourse-based view of the language of written advertisements involves teachers and learners, in (E)FL classroom, looking not just at isolated decontextualized bits of language, but examining how bits of language contribute to the making of complete advertisement texts. It involves exploring the relationship between the linguistic patterns of complete advertising texts and the social contexts in which they function. It, also, involves considering the higher-order operations of advertising language at the interface of cultural and ideological meanings and returning to the lower order forms of advertising language which are crucial to the patterning of such meanings (figure 1). A discourse-based view of advertising language also prioritizes an interactive approach to analysis of advertising texts, which considers the dynamism inherent in the advertising linguistic context.

Moreover, if language awareness can be and should be more extensively introduced into the language classroom using whole written advertisement texts, so that (E)FL learners should benefit (sections 3;4;5), then it is unlikely to be successful if it is seen as a separate classroom activity not integrated into the ongoing process of language learning. However, the question is how this integration could be achieved so as to be beneficial for learners, specifically, what is the relevance for language awareness and language teaching. McCarthy and Carter (1994: 164) propose three parameters of language awareness for all kinds of texts, that of form, function and socio-cultural meaning, which, I think, are neither exclusive nor discrete. I adapt them to the 
demands of advertising text considering that the latter uses language to implement their short or long run function of selling.

\subsection{The form parameter}

Activities within the parameter form involve a focus on formal aspects of advertising language as well as looking at advertising language as a system considering simultaneously the 'always arbitrariness ... in the relations between form and meaning' (McCarthy \& Carter, 1994: 163). Advertisements use positive vocabulary familiar to the consumption community they address so as to become memorable.; e.g. fresh, sport, continent, together be, etc., what Carter (1987cited in Delin, 2000: 132) terms 'core vocabulary'. In English, a good example could be: you can have 'a strong/powerful argument', 'a powerful car' but you cannot have * 'a strong car' '(ibid.). These lexical gaps could be exploited using activities which could, firstly, highlight the contrasts and gaps internal to the target language drawing learners' attention to 'what is there and what is not there' (ibid.), and secondly, bring into conscious awareness contrasts or related patterns within the learners' L1 and L2. Concerning the examined data (section 2), for example, the phrase 'joined together' evokes positive associations and evaluation while its illustrative candidate synonym 'combine' evokes negative associations and evaluation ,because it has the indication of mingling/blending, implying identity losing and becoming merged in each other. The same happens with 'ALLURE' (verb) and its illustrative candidate synonym 'attract' as well as 'fresh' and its illustrative synonym candidates 'raw; immature'.

\subsection{The function parameter}

Activities within the function parameter may raise learners' awareness of what language does in advertisements, because they involve the relationship between language and contexts in use. For example, the fact that advertisements are parasitic upon their surroundings and other genres, discussed in section 5 gives several classroom possibilities for comparison. For example, if learners compare and discover how ellipsis (used and discussed in the three examined advertisements) is used in real speech and/or written language, and/or advertisements, that is, how the same phenomenon is used for different purposes and functions, then language learning might benefit. 'Again' (sub-section 2.4) could be highlighted similarly.

\subsection{Socio-cultural meaning parameter}

McCarthy and Carter (1994: 164) argue that socio-cultural meaning is best achieved by invoking the contrastive principle. Examples may include activities which contribute to language awareness cross-culturally. Concerning findings of the discussed advertisements in section 2, textbook designers and/or teachers could encourage learners to compare, for example, how lexico-grammar is used to : promote men vs women' $\mathrm{s}$ perfumes ; by air companies or banks of different nationality to promote their advertised services. These advertisements could be either in English(L2) or a combination of L2 and L1. That means that comparison could take place between L1 versus L2 or L2 versus L2. Both kinds of cultural exploitation are beneficial for language learning (sections 5.1 and 5.2).

\section{Conclusion}

Indisputably, the qualitative study presented of this article has many limitations and can reach no generalizations. The limitations are interrelated and reside in its size, research findings and research method. Illustratively, the obvious disadvantage of a 
small size convenience sampling is that it is likely to be biased and should not be taken to be representative of all advertisements. Also, the study carries out structural analysis focusing on the advertisement body-copy. However, following illustrative discussion in sections 1; 3; 4 among the different advertisement components there is inter and intra-relation. Moreover, the analysis is not detailed, for example, the fact that the CHANEL body copy is printed in capitals is not discussed, etc. Despite limitations, this piece study has the potential to act as a springboard both for further research regarding, for example, socio-advertising cultural dimensions (see e.g., 6.3), as well as encourage teaching/learning implications.

Concerning the latter the discussed, in section 6, parameters could integrate a discourse based view of the language of commercial written whole advertisements into the ongoing process of language learning in EFL classroom, because they exploit the quality and quantity of advertising texts as well as the frequency of advertising languageregarding its parasitic behavior upon other genres to carry out the functions of advertising text, namely to sell (briefly discussed in section 5).

It is quite clear in relation to the above discussion that the exploitation of advertising texts to develop activities which encompass the linguistic, cultural and sociolinguistic domain of language- namely, activities based on discourse analysis- enables and encourages language learning. This happens because this type of activities, firstly, enables learners to develop language awareness through learning about language; indispensable successive steps encouraging and leading to language learning; and secondly, is based on frequency, repetition and comparison between L2 vs L2 and L2 vs L1 all contributing to language learning.

\section{References}

Bax, S. (2011). Discourse and Genre. Palgrave: England.

Bhatia, V.K. (2007). Worlds of Written Discourse. London: Continuum.

Cook, G. (2009). The Discourse of Advertising. $2^{\text {nd }}$ Ed. London, USA, Canada: Routledge.

Delin, J. (2002). The Language of Everyday Life. London: Sage.

Dörnyei, Z. (2011). Research Methods in Applied Linguistics. Oxford: Oxford.

Fairclough, N. (1989). Language and Power. London: Longman.

Fairclough, N. (2009). Discourse and Social Change. UK: Polity Press.

Goddard, A. (2006). The Language of Advertising. Abingdon: Routledge.

Harman, R. (2013). Literary intertextuality in genre-based pedagogies: Building lexical cohesion in fifth grade L2 writing. Journal of Second Language Writing 22:125-140.

Hayland, K. (2007). Genre pedagogy: Language, literacy and L2 writing instruction. Journal of Second Language Writing: 148-164.

Hedge, T. (2008).Teaching and Learning in the Language Classroom. Oxford: OUP.

Johnstone, B. (2011). Discourse Analysis. Place of Publication: Blackwell Publishing.

Le Nouveau Petit Robert de la langue française. (2007). Paris : Le Robert.

McCarthy, M. \& Carter, R. (1994). Language as Discourse, Perspectives for Language Teaching. London: Longman.

Myers, G. (1994). Words in Ads. London: Edward Arnold.

Picken, J. (1999). State of the ad: the role of advertisements in EFL teaching.

ELT Journal 53/4: 249-255.

Stamatelou, M. (2015). A reflection on the use of advertisements in enabling

language learning in EFL classroom. ELTED Journal 17; 27-34.

'The Economist' (2007). The World in 2007; Source $21^{\text {st }}$ Edition. www.economist.com

Thornbury, S. (2002). About Language. United Kingdom: Cambridge University Press.

Thornbury, S. (2005). Beyond the Sentence. Oxford: McMillan.

Toolan, M.(1988). 'The language of press advertising' in M. Ghadessy (ed.),Registers of Written English. London and New York: Pinter.52-64.

Yule, G. (2008). Pragmatics. New York: Oxford. 